\title{
ECOLOGICAL AGRICULTURE DEVELOPMENT AND SPATIAL AND TEMPORAL CHARACTERISTICS OF CARBON EMISSIONS OF LAND USE
}

\author{
SUN, Q. - LIAO, B. - TAO, Q. Y.* \\ Management College, Beijing Union University, Beijing 100101, China \\ ${ }^{*}$ Corresponding author \\ e-mail: qytaomail@163.com
}

(Received $1^{\text {st }}$ Apr 2019; accepted $13^{\text {th }}$ Jun 2019)

\begin{abstract}
With the continuous development of society, the agricultural economy has shown a good development trend, but at the same time it has produced more and more carbon emissions, and the greenhouse effect has increased, posing a threat to the ecological environment. Agricultural carbon emissions are important factors. Therefore, studying the temporal and spatial characteristics of agricultural carbon emissions is an urgent task. This paper focused on agricultural carbon emissions from land use and tested and predicted future carbon emissions based on three types of carbon source factors using the auto regressive integrating moving average (ARIMA) model. The spatial and temporal characteristics of agricultural carbon emissions were analyzed from the dimension of time and space. According to the results, the total agricultural carbon emission and intensity of the eastern region ranked the first, followed by the middle region; the total agricultural carbon emission of different regions increased, but slower; the agricultural carbon emission intensity of different regions decreased, and overall decreased faster. This study effectively verifies the deep influence of the development of ecological agriculture on the spatial and temporal characteristics of carbon emission of land use.
\end{abstract}

Keywords: ecological environment, carbon source factor, temporal sequence prediction, economic system, temporal and spatial characteristics

\section{Introduction}

In the process of agricultural economic development, the impact of land use change on greenhouse gas emissions has become a core issue in today's carbon cycle research. With the emergence of these phenomena, a series of social and environmental problems have arisen, and the situation of agricultural development is very worrying. Therefore, research on the temporal and spatial characteristics of carbon emissions of land use is extremely urgent (Simmons and Matthews, 2016). In response to this problem, many experts and scholars have put forward their own opinions. Zhang and Fang (2013) effectively assessed and predicted agricultural carbon emissions based on six relevant aspects of agricultural carbon sources, put forward the research method of decomposition factor based on kaya model, and found that the rapid development of agricultural economy increased carbon emission. Liu et al. (2014) proposed a model which was composed of gray model $(\mathrm{GM})(1,1)$ model, auto regressive integrating moving average (ARIMA) model and second order polynomial regression (SOPR) model to predict and analyze the carbon emission intensity of carbon dioxide. Han et al. (2018) believed that there was an inevitable connection between agricultural carbon emissions and agricultural economic growth and put forward the study of the coupling and decoupling effects of agricultural carbon emissions and their driving factors. Chuai et al. (2015) believed that the change of land use type would not only directly affect the carbon stocks in terrestrial ecosystems, but also had an indirect impact on the frequent occurrence of anthropogenic carbon emissions in coastal areas. Therefore, a linear 
programming model was proposed to improve the land use structure and achieve the goal of low carbon emissions. Gong and Chen (2011) analyzed the status of carbon emissions and proposed suggestions of land use regulation based on low-carbon emissions: setting up and optimizing land ecological compensation mechanisms, etc., which is conducive to promoting carbon emission reduction and protecting the ecological environment. In this study, the agricultural carbon emission was analyzed and predicted based on the three kinds of carbon source factors of agricultural carbon emission and ARIMA model, and the spatiotemporal distribution characteristics of agricultural carbon emissions were clearly illustrated. This work provides a reference for the development of ecological agriculture in China.

\section{Materials and methods}

\section{Development of ecological agriculture}

Agriculture is the foundation of a country's foothold, which realizes the basic material data needs of human beings by converting biology into solar energy. While the efficiency of agricultural production is constantly improving, the ecological environment has been sacrificed, which has caused great threats to human beings. In order to slow down the severity of this phenomenon, a scientific and standardized ecological agriculture has been emerged. Ecological agriculture refers to a modern agricultural development mode which combines systematic engineering methods with modern scientific achievements, strictly follows the growth law of ecological economy, is based on the basic principles of ecology, and has the intention of protecting and improving agricultural ecological environment (Wu et al., 2015). It is a project involving multiple aspects, such as economic science and natural science (Onofrei et al., 2016).

The most important feature of eco-agricultural production is ecological character, in which the effect of protecting the ecological environment is significant, but the production efficiency is not very high when the input cost is high. The purpose of ecoagriculture development include protecting the ecological environment and promoting high-productivity and high-ecological double harvest. Therefore, a sustainable, scientific and efficient agricultural development model was developed by combining ecological agriculture with China's national conditions and using modern scientific management tools, and moreover the advantages of every area are taken as the emphatically developed agricultural projects to implement regional eco-agricultural construction, which can effectively protect ecological environment while obtaining large economic benefits and promote the harmonious development of society.

\section{Carbon emissions of land use}

Applying land to different application areas, such as planting crops, raising livestock, developing waters, and building high-rise buildings, will result in different types of land use, and changes in land use will have different carbon emission effects. The so-called land-use carbon emissions refers to the carbon dioxide released by changes in the field of land application and people on the land in their production and life (Fu et al., 2017), in a direct or indirect way. Direct carbon emissions represents carbon emissions from changes in land use cover and land management concepts and methods; indirect carbon emissions represents carbon emissions of human activities in different types of land use 
(Kato and Yamagata, 2014). Carbon emission of land use is expressed as $E(t)$, the carbon emission of type $a$ land use is expressed as $e_{a}(t)$, the area of type $a$ land use is expressed as $S_{a}\left(\mathrm{hm}^{2}\right)$, and the carbon emission coefficient of type $a$ land use $\left(\mathrm{t} / \mathrm{hm} \mathrm{m}^{2}\right)$ is expressed as $\delta_{a}$. Then the computational formula of carbon emission of different types of land use is:

$$
E=\sum e_{a}=\sum S_{a} \delta_{a}
$$

Agricultural carbon emission is an important part of carbon emission of land use. Therefore, this study investigated carbon emission of land use by focusing on agricultural carbon emission. Agricultural carbon emission is mainly analyzed through three types of carbon source factors, including carbon emission of agricultural land use, carbon emission of paddy fields, and carbon emission of livestock farming (Han et al., 2018). The carbon emission of agricultural land use mainly include carbon emission of chemical products such as pesticides, agricultural film and chemical fertilizers, organic carbon emission produced by the damage of ploughing activities to soil organic carbon pool, and carbon emission produced by electric energy loss and loss of energy such as diesel during farming by agricultural machinery. Specific carbon sources include pesticide inputs and their changes, fertilizer inputs and their changes, agricultural irrigation inputs and their changes, agricultural land cultivation methods and their changes, and agricultural machinery products inputs and changes (Ismael et al., 2018). Carbon emissions from paddy field planting mainly include carbon emission from rice planting in different growth cycles, early rice, late rice and mid-season rice. The main carbon sources in livestock farming are intestinal fermentation of livestock and poultry and livestock manure (Asumadu-Sarkodie and Owusu, 2017).

\section{Spatial distribution}

Through the collection and sorting of relevant data on agricultural carbon emissions, the agricultural carbon emission areas are generally divided into four levels, including low agricultural carbon emission areas, medium agricultural carbon emission areas, slightly high agricultural carbon emission areas and high agricultural carbon emission areas. It can be seen from Fig. 1 that the high agricultural carbon emission areas are mainly distributed in provinces such as Sichuan, Shandong, Jiangsu, Anhui, Hunan and Hubei, the slightly high agricultural carbon emission areas are mainly distributed in provinces such as Inner Mongolia, Heilongjiang, Yunnan, Guangdong and Jiangxi, the medium agricultural carbon emission areas are mainly distributed in provinces such as Gansu, Shaanxi, Zhejiang, Fujian, Jilin and Liaoning, and the low agricultural carbon emission areas are mainly distributed in provinces such as Qinghai, Shanxi and Hainan (Pang and Zhao, 2013). The agricultural carbon emissions of the eastern region account for a large proportion, followed by the central region and western region, which has a great relationship with factors such as climate, economy and environment. The change of every factor will produce different agricultural phenomena and development effects. As the eastern region has good climatic conditions, excellent economic environment and fast agricultural development, the proportion of the agricultural carbon emission of the eastern region is larger than that of the other two regions.

Relevant data on agricultural carbon emissions in the eastern, central and western regions in 2015 were collected and sorted, and experimental results were obtained based 
on the algorithm of agricultural carbon emissions. The experimental data mainly consisted of carbon emissions generated by different chemical products in agricultural land use, carbon emissions generated by the rice planting process in different periods, carbon emissions generated by livestock breeding and total agricultural carbon emission. Moreover deep study was carried out to analyze the spatial difference characteristics of different regions in the dimension of space, and corresponding experimental conclusions were obtained.

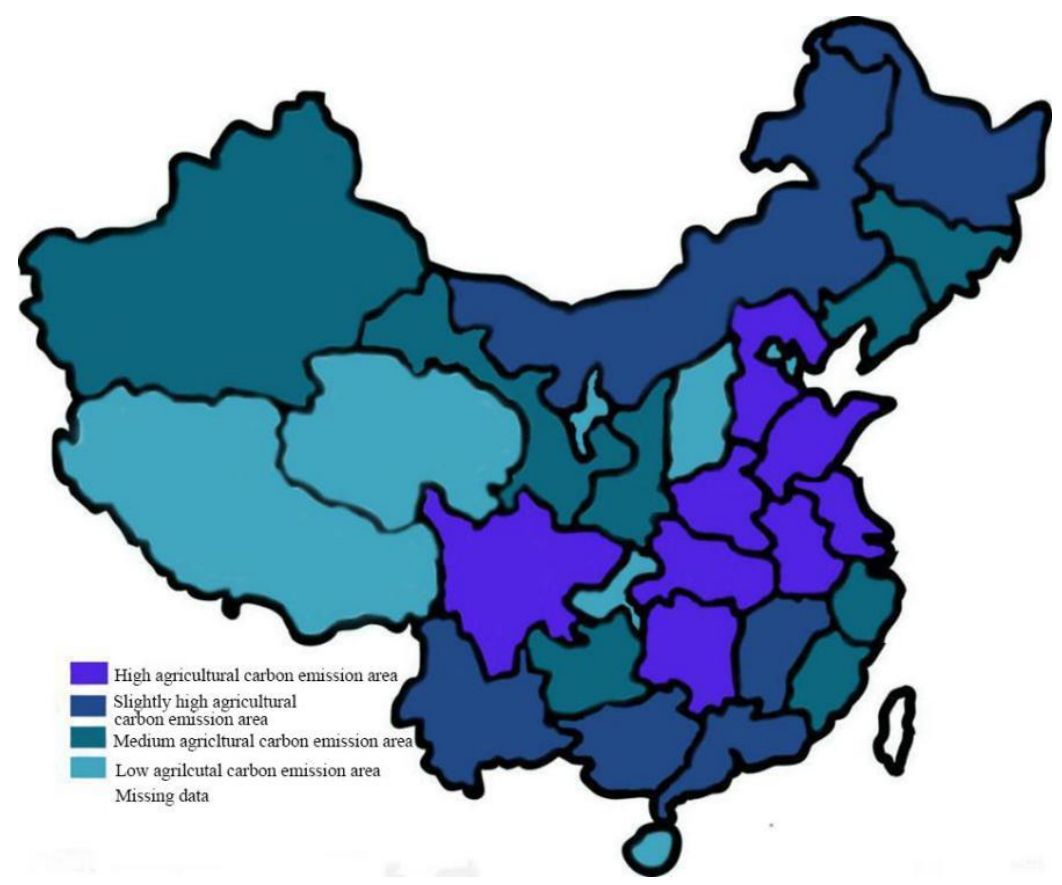

Figure 1. Spatial distribution characteristics of China's agricultural carbon emissions

\section{Temporal distribution}

Methods for analyzing the temporal sequence characteristics of agricultural carbon emissions

With the rapid development of the agricultural economy, China's agricultural carbon emissions are generally on the rise, and the government's agricultural policy has always placed food security as a top priority to meet China's demand for food. In 2004, the relevant government departments promulgated a number of policies conducive to the agricultural economy and did not forget to promote the development of agriculture while making rapid progress in society. In 2006, the government completely abolished the agricultural tax to promote the enthusiasm of farmers. However, in the environment of rapid development of agriculture and with the continuous improvement of production efficiency, a series of negative phenomena have emerged, such as the sacrifice of the ecological environment; hence the government has paid more and more attention to the protection of the ecological environment. In 2007, the 17th National Congress of the Communist Party of China was fully convened, and the importance of protecting the ecological environment was strongly emphasized. So far, ecological agriculture has continued to develop, and the business philosophy has been moving closer to scientific and normative. The various factors will affect the changes in agricultural carbon 
emissions, mainly reflected in the characteristics of time distribution. Therefore, this paper studied the temporal and spatial sequence characteristics of agricultural carbon emissions from the total amount and intensity of agricultural carbon emissions.

Data on agricultural carbon emissions in the eastern, central and western regions from 2012 to 2018 were collected and sorted, and the corresponding calculation was made to obtain experimental results. Moreover, the simulation experiment of prediction was made using EViews9.0. The corresponding ARIMA model was established. A time series was established and tested. Then the relevant parameters of the model were compared, diagnostic test was made, and the total amount and intensity of agricultural carbon emissions from 2019 to 2025 was predicted. The corresponding verification results were obtained, and the temporal distribution characteristics of agricultural carbon emissions in the eastern, central and western regions were analyzed, and the corresponding experimental conclusions were obtained for reference.

\section{Prediction of agricultural carbon emissions}

Agricultural carbon emissions in the eastern, central and western regions from 2019 to 2025 were predicted using ARIMA model. The model can be used for time series prediction. It is established by transforming the non-stationary time series into the stationary time series, regressing the lag value, and implementing the regression operation on the present value and the lag value of the random error term. In $\operatorname{ARIMA}(\mathrm{p}, \mathrm{d}, \mathrm{q}), p$ is autoregressive item, $q$ is the number of moving average items, $d$ is the number of differences made when the time series is converted to be stationary, ${ }^{\varepsilon_{t}}$ is a stationary time series, and $u_{t}$ is the residual white noise sequence, and $\phi_{m}$ and $\theta_{m}(i=1,2, \cdots, p, m=1,2,3, \cdots, q)$ are ${ }^{\varepsilon_{t}}$ and the parameter of ${ }^{\varepsilon_{t}}$. The calculation formula is:

$$
\varepsilon_{t}=c+\phi \varepsilon_{t-1}+\phi \varepsilon_{t-2}+\cdots+\phi_{p} \varepsilon_{t-p}+u_{t}+\theta_{1} u_{t-1}+\theta_{2} u_{t-2}+\cdots+\theta_{q} u_{t-q}
$$

The prediction steps are as follows. Firstly, the original sequence $A D F$ was tested and verified. If there was a unit root, then in order to make it meet the stability conditions, $d$-order differential operation was made on the initial sequence. Then the correlation study was made on the characteristics of sequence after differential operation. Moreover the values of $p$ and $q$ were obtained through the autocorrelation function and partial autocorrelation function graphs of sequence. Dependent variable $A R(p)$ and $M A(q)$ were estimated by least square estimation or maximum likelihood estimation. Diagnostic test was performed on the residual of the mode. Finally the data of agricultural carbon emission was predicted.

\section{Results}

\section{Analysis of spatial characteristics of carbon emission}

The spatial characteristics of agricultural carbon emissions in the eastern, central and western regions in 2015 were analyzed, and the results are shown in Table 1 (unit: tens of tons).

It can be seen from Table 2 that the carbon emissions of agricultural land use in the eastern and central regions accounted for the largest proportion, followed by the carbon emission of paddy field planting and livestock breeding. The carbon emission of 
livestock farming in the western region accounted for the largest proportion, followed by the carbon emission of agricultural land use and paddy field planting. In general, there were differences between regions. The eastern and central regions have high land utilization rate because of the large area of plains, and the climatic conditions for rice planting are good; therefore the carbon emissions of agricultural land use and paddy field planting were high. The western region has low land utilization rate because of the high altitude. Moreover the climate conditions for rice planting are bad. But the broad meadow resources are suitable for the breeding of livestock such as cattle and sheep. Therefore the carbon emissions of livestock breeding in the western region was high.

Table 1. Spatial differences in agricultural carbon emissions in the eastern, central and western regions

\begin{tabular}{c|c|c|c|c}
\hline & $\begin{array}{c}\text { Carbon emission of } \\
\text { agricultural land use }\end{array}$ & $\begin{array}{c}\text { Carbon emission of } \\
\text { paddy field planting }\end{array}$ & $\begin{array}{c}\text { Carbon emission of } \\
\text { livestock breeding }\end{array}$ & $\begin{array}{c}\text { Total agricultural } \\
\text { carbon emission }\end{array}$ \\
\hline $\begin{array}{c}\text { The eastern region } \\
\text { The central region }\end{array}$ & 12078.36 & 7512.98 & 3498.35 & 23089.69 \\
$\begin{array}{c}\text { The western } \\
\text { region }\end{array}$ & 8102.98 & 5236.12 & 3857.26 & 17196.36 \\
\hline
\end{tabular}

Table 2. Temporal differences of agricultural carbon emissions in the eastern, central and western regions

\begin{tabular}{c|c|c|c|c|c|c}
\hline Year & $\begin{array}{c}\text { Total of } \\
\text { eastern }\end{array}$ & Total of central & $\begin{array}{c}\text { Total of } \\
\text { western }\end{array}$ & $\begin{array}{c}\text { Intensity of } \\
\text { eastern }\end{array}$ & $\begin{array}{c}\text { Intensity of } \\
\text { central }\end{array}$ & $\begin{array}{c}\text { Intensity of } \\
\text { western }\end{array}$ \\
\hline 2012 & 10023.69 & 8523.56 & 7123.89 & 57.98 & 53.98 & 47.26 \\
2013 & 15756.19 & 12619.55 & 12036.25 & 56.78 & 52.19 & 46.96 \\
2014 & 20523.56 & 16169.63 & 15369.36 & 55.78 & 51.06 & 45.02 \\
2015 & 23089.69 & 17196.36 & 16369.18 & 54.06 & 50.97 & 43.46 \\
2016 & 23965.36 & 18636.78 & 16987.16 & 49.87 & 47.56 & 40.12 \\
2017 & 24579.63 & 19369.43 & 17693.98 & 45.99 & 43.99 & 37.98 \\
2018 & 25969.36 & 20869.58 & 18996.78 & 37.02 & 36.09 & 32.13 \\
\hline
\end{tabular}

In 2015, the total amount of agricultural carbon emissions in the eastern region ranked the first, followed by the central region. The total amount of agricultural carbon emission in the western region was the smallest compared with the other two regions, and the differences between the regions were large. The eastern region, compared with the central and western regions, has superior economic environment, larger scale of agriculture and higher modern technology level, which makes agricultural carbon emissions increase; therefore, the total amount of agricultural carbon emissions was the largest. In comparison, the western region had the poorest condition in those aspects; hence the total agricultural carbon emission was the smallest.

\section{Analysis of temporal characteristics of carbon emission}

The temporal characteristics of agricultural carbon emissions in the eastern, central and western regions from 2012 to 2018 were analyzed, and the results are shown in Table 2 (unit of the total carbon emission: ten thousand tons; unit of carbon emission intensity: $\mathrm{kg} / \mathrm{mu})$. 
It can be seen from Table 2 that the total amount of agricultural carbon emissions in the eastern, central and western regions was generally on the rise from 2012 to 2018, because the scale of agriculture in each region was expanding and the industrial technology was effectively improved. However, the growth rate of the total carbon emissions has slowed down, and the phenomenon of agricultural carbon emission has improved, which is because that China's agricultural policy is constantly adjusted, the popularization rate of ecological agriculture management concept has been greatly improved, and the development mechanism of ecological agriculture has been continuously optimized and improved.

From 2012 to 2018, the carbon emission intensity in the eastern, central and western regions showed a downward trend. Moreover, it can be seen that the decline amplitude in carbon intensity in different regions became larger, which is because that the government tends to pay more attention to environmental protection and release lowcarbon agriculture related policies and the mechanism of ecological agriculture becomes more and more scientific.

\section{Prediction of agricultural carbon emissions}

A simulation experiment was conducted on the total amount and intensity of agricultural carbon emissions in the eastern, central and western regions from 2019 to 2025, and the results are shown in Table 3 (unit of the total carbon emission: ten thousand tons; unit of carbon emission intensity: $\mathrm{kg} / \mathrm{mu}$ ).

As can be seen from Table 3, from 2019 to 2025, the total amount of agricultural carbon emissions in the eastern, central and western regions increased, but the magnitude tended to be gentle. The gentle increase is because that the continuous development of ecological agriculture has promoted the development of low-carbon economy, and the agricultural management concept is moving closer to the new mode of low input and high production. But the pace of developing the agricultural economy cannot be stopped; therefore, the agricultural carbon emissions has an increase.

Table 3. Prediction of agricultural carbon emissions in the eastern, central and western regions

\begin{tabular}{c|c|c|c|c|c|c}
\hline Year & $\begin{array}{c}\text { Total of } \\
\text { eastern }\end{array}$ & Total of central & $\begin{array}{c}\text { Total of } \\
\text { western }\end{array}$ & $\begin{array}{c}\text { Intensity of } \\
\text { eastern }\end{array}$ & $\begin{array}{c}\text { Intensity of } \\
\text { central }\end{array}$ & $\begin{array}{c}\text { Intensity of } \\
\text { western }\end{array}$ \\
\hline 2019 & 26001.36 & 22009.39 & 20012.96 & 37.01 & 35.94 & 32.06 \\
2020 & 27098.35 & 24005.98 & 22080.45 & 36.96 & 35.69 & 31.96 \\
2021 & 28809.36 & 25065.12 & 23601.78 & 36.75 & 35.36 & 31.65 \\
2022 & 29500.96 & 25956.45 & 24806.95 & 36.19 & 35.02 & 31.08 \\
2023 & 29769.36 & 26963.47 & 25102.69 & 35.32 & 34.01 & 30.56 \\
2024 & 30002.23 & 27965.15 & 25672.63 & 34.59 & 33.09 & 29.56 \\
2025 & 30400.79 & 28137.65 & 26012.73 & 32.01 & 31.01 & 28.46 \\
\hline
\end{tabular}

The intensity of agricultural carbon emissions in the eastern, central and western regions generally declined, and the decline amplitude became larger. The reason is that the change of agricultural policy has made the concept of eco-agriculture economy more and more popular and more and more attention is paid to the protection of the ecological environment during the development of agricultural economy, which makes the intensity of agricultural carbon emission low. 
Generally speaking, with the rapid development of China's eco-agriculture and the high popularity of the concept of protecting the ecological environment, the severe phenomenon of China's agricultural carbon emissions will continue to improve, especially in the aspects of agricultural carbon emission amount and intensity. The improvement of agricultural carbon emissions will affect the carbon emissions of land use, and moreover the ecological agricultural economic system will continue to be optimized to promote the healthy development of agriculture.

\section{Conclusion}

With the rapid development of the agricultural economy, the ecological environment has deteriorated and the carbon emissions of agriculture have increased. Therefore, the research on the temporal and spatial characteristics of land use carbon emissions has developed into an important research topic. Studying this topic can grasp the temporal and spatial characteristics of agricultural carbon emissions in various regions and help effectively optimize and improve the relevant mechanisms of agricultural carbon emissions. This paper mainly focused on agricultural carbon emissions among carbon emissions of land use, compared and analyzed the three types of carbon source factors based on agricultural carbon emissions, analyzed the spatial and temporal characteristics of agricultural carbon emissions in the eastern, central and western regions, and established an ARIMA model. The total amount and intensity of agricultural carbon emissions in the western, central and middle regions were predicted and analyzed. It was found that the total carbon emission amount and intensity in the eastern region were the highest, followed by the central region, the total agricultural carbon emissions of all the regions increased, but in a gentle amplitude, and the agricultural carbon emission intensity of all the regions decreased in a fast speed. The study of the spatial and temporal characteristics of carbon emissions of land use is conducive to promoting the efficient development of ecological agriculture in the future.

\section{REFERENCES}

[1] Asumadu-Sarkodie, S., Owusu, P. A. (2017): The causal nexus between carbon dioxide emissions and agricultural ecosystem-an econometric approach. - Environ Sci Pollut Res Int 24(2): 1608-1618.

[2] Chuai, X., Huang, X., Wang, W., Zhao, R., Zhang, M., Wu, C. (2015): Land use, total carbon emissions change and low carbon land management in Coastal Jiangsu, China. Journal of Cleaner Production 103: 77-86.

[3] Fu, B., Wu, M., Che, Y., Yang, K. (2017): Effects of land-use changes on city-level net carbon emissions based on a coupled model. - Carbon Management 1-18.

[4] Gong, B., Chen, B. (2011): The Regulation Analysis of Low-Carbon Orientation for China Land Use. - Computer \& Computing Technologies in Agriculture IV: 602-609.

[5] Han, H., Zhong, Z., Guo, Y., Xi, F., Liu, S. (2018): Coupling and decoupling effects of agricultural carbon emissions in China and their driving factors. - Environmental Science \& Pollution Research International 2018(9): 1-14.

[6] Ismael, M., Srouji, F., Boutabba, M. A. (2018): Agricultural technologies and carbon emissions: evidence from Jordanian economy. - Environmental Science and Pollution Research 25(11): 10867-10877. 
[7] Kato, E., Yamagata, Y. (2014): BECCS capability of dedicated bioenergy crops under a future land-use scenario targeting net negative carbon emission. - Earth's Future 2(9): 421-439.

[8] Liu, L., Zong, H., Zhao, E., Chen, C., Wang, J. (2014): Can China realize its carbon emission reduction goal in 2020: From the perspective of thermal power development. Applied Energy 124: 199-212.

[9] Onofrei, V., Teliban, G. C., Balan, C. B., Ropotoaia, I., Buburuz, A. A., Clinciu-Rad, R. A., Robu, T. (2016): Necessity, Desirability and Importance of Ecological Agriculture in the Context of Medicinal Plants Cultivation. - Bulletin of University of Agricultural Sciences and Veterinary Medicine Cluj-Napoca. Agriculture 73(1).

[10] Pang, L., Zhao, J. (2013): An Empirical Study on China's Regional Carbon Emissions of Agriculture. - International Journal of Asian Business and Information Management (IJABIM) 4.

[11] Simmons, C. T., Matthews, H. D. (2016): Assessing the implications of human land-use change for the transient climate response to cumulative carbon emissions. Environmental Research Letters 11(3): 035001.

[12] Wu, H., Zhang, Y., Yuan, Z., Gao, L. (2015): A review of phosphorus management through the food system: identifying the roadmap to ecological agriculture. - Journal of Cleaner Production S095965261501001X.

[13] Zhang, Y., Fang, G. (2013): Research on Spatial-Temporal Characteristics and Affecting Factors Decomposition of Agricultural Carbon Emission in Suzhou City, Anhui Province, China. - Applied Mechanics and Materials 291-294: 1385-1388. 